\title{
Thermal Volatilisation Analysis of TDI-based Flexible
}

\section{Polyurethane Foam}

\section{Allan ${ }^{1}$, J. Daly, J. J. Liggat ${ }^{1}$}

${ }^{1}$ WestCHEM, Department of Pure and Applied Chemistry, University of Strathclyde, 295 Cathedral Street, Glasgow G1 1XL, UK

AUTHOR E-MAIL ADDRESSES: Deborah Allan - DAllan@insigniatechnologies.com; John J. Liggat -j.j.liggat@strath.ac.uk;

*CORRESPONDING AUTHOR FOOTNOTE. Ph: +44 (0)1415485774 Fax: +44 (0) 1415484822 email: j.j.liggat@strath.ac.uk;

\section{ABSTRACT:}

The thermal degradation behaviour of a polyurethane foam, synthesised from TDI and a polyether polyol, is reported. The thermal degradation behaviour of this material was evaluated by a combination of thermogravimetric analysis (TGA) and thermal volatilisation analysis (TVA). The results demonstrated that the thermal degradation is a complex process which consists of competing mechanisms which yield an array of degradation products. The TVA results revealed that the degradation occurs in two steps, with the initial step corresponding to degradation of the urethane linkages by two competing mechanisms. The first mechanism, proposed to be the predominant mechanism, involves simple depolymerisation of the urethane bond to yield TDI and polyol. A second, competing mechanism is proposed to occur which involves dissociation of the urethane linkages to yield 
DAT, $\mathrm{CO}_{2}$ and alkene-terminated polyol chains. The second degradation step has been shown to involve degradation of the polyol which was regenerated in the first degradation step. This is proposed to occur by random radical chain scission of the polyol to yield propene, formaldehyde, acetaldehyde, $\mathrm{C}_{3} \mathrm{H}_{6} \mathrm{O}$ isomers and high molar mass polyol chain fragments of various structures. Isothermal TVA studies have revealed that this occurs as low as $250^{\circ} \mathrm{C}$ under vacuum but does not become significant until temperatures greater than $300^{\circ} \mathrm{C}$.

\section{KEYWORDS:}

Polyurethane foam; TDI; evolved gas analysis, mechanism 


\section{INTRODUCTION}

Polyurethanes are one of the most versatile classes of polymers which find vast use in today's society. However, a major drawback of these materials is their ease of flammability and the toxic nature of the gases which are evolved. Polyurethane foams, in particular, are widely used in upholstery and home furnishings and, as a result, are often major contributors to fires. At present there are effective fire retardant formulations available, although many of these are now regarded as environmentally unacceptable. There is, therefore, the need to develop new formulations for use in polyurethane foams. The behaviour of a polymer in a fire is closely associated with its degradation behaviour and, as a result, much research has been conducted to study the thermal stability and degradation of polyurethane materials. The chemistry occurring during the degradation, and the effect of fire retardants on this process, must be fully understood if fire retardant systems are to be effectively employed. Polyurethane foams are complex materials which contain a variety of functional groups (e.g. urethane, urea, biuret, allophonate) that lend the foams different physical properties and which can even vary across the crosssection of a foam as a result of temperature gradients during processing. [1-3] The thermal degradation of polyurethane is, therefore, unsurprisingly complex; it depends on the structure of the material, making it strongly dependent on the type of polyol or polyisocyanate from which it is synthesised. The presence of additives, such as fire retardants, can also significantly affect the degradation processes which occur.

It is generally accepted throughout the literature that the purely thermal degradation of the urethane linkages within polyurethane (the primary degradation step) occurs between $200^{\circ} \mathrm{C}$ and $250^{\circ} \mathrm{C}$ by one or more of the three mechanisms shown in Figure 1. [4-7] Reaction I involves the breaking of one $\mathrm{N}-\mathrm{H}$ bond $\left(386 \mathrm{~kJ} \mathrm{~mol}^{-1}\right)$ and one $\mathrm{C}-\mathrm{O}$ bond $\left(358 \mathrm{~kJ} \mathrm{~mol}^{-1}\right)$. Reaction II on the other hand requires a greater input of energy in order to break the C-N $\left(305 \mathrm{~kJ} \mathrm{~mol}^{-1}\right), \mathrm{C}-\mathrm{O}\left(358 \mathrm{~kJ} \mathrm{~mol}^{-1}\right)$ and C-H $(411 \mathrm{~kJ}$ $\left.\mathrm{mol}^{-1}\right)$ bonds. Reaction 3 is the least energetic involving the rupture of a $\mathrm{C}-\mathrm{N}\left(305 \mathrm{~kJ} \mathrm{~mol}^{-1}\right)$ and a C-O $\left(358 \mathrm{~kJ} \mathrm{~mol}^{-1}\right)$ bond. It has been reported by many authors that the depolymerisation reaction (I) is the predominant degradation reaction for the urethane linkage. [4, 5, 7-9] If depolymerisation occurs the diisocyanate will be the major volatile species which can be evolved, although it can also undergo 
secondary decomposition reactions. Depolymerisation of the urethane linkages would leave a residue containing almost exclusively regenerated polyol. If, on the other hand, the diisocyanate cannot volatilise it will become trapped within the pyrolysis zone and the reverse of reaction I can occur, i.e. the polyol and isocyanate can recombine to reform the urethane bond, and equilibrium would therefore become established. It has been reported in this situation that mechanism II, which is slower but irreversible, would become the more favoured reaction [4,5] and the major degradation products evolved would be an amine and $\mathrm{CO}_{2}$. In this case the residue would resemble the polyol but with an unsaturated end group. It has also been reported that degradation via mechanism II can become predominant if the alcohol or polyol employed has a $\beta$-hydrogen.[10,11] There have, however, been few reports of mechanism III occurring to any great extent.

Following the primary degradation step, the polyol or polyol-based material generated will then undergo degradation reactions to produce secondary degradation products. The majority of polyether polyols employed in the production of flexible polyurethane foams are derived from poly(propylene oxide) (PPO) and poly(ethylene oxide) (PEO), or co-polymers thereof. $[12,13]$ These materials are believed to undergo thermal degradation via random homolytic chain scission along the polymer backbone to yield a variety of degradation products containing hydroxyl, carboxyl, carbonyl and ether groups. [14-17]

A number of studies have been published on the thermal degradation chemistry of polyurethane materials; however, the literature concerning the degradation of foams is limited. The majority of studies have been concerned with elastomers and model compounds usually containing only one functional group, such as a urethane bond. In particular, there is more limited knowledge on the processes which occur during the degradation of toluene diisocyanate (TDI) based foams as most studies have been conducted on methylene diphenyl diisocyanate (MDI) based materials. This is despite the fact that TDI is the isocyanate of choice for the majority of flexible foam formulations in the UK and North America. In this communication we report on the thermal degradation behaviour of a TDI-based 
polyurethane foam with the aim of expanding on the limited knowledge available on these systems. The thermal stability and degradation mechanisms of this material have been studied in detail, with particular use of the technique of thermal volatilisation analysis (TVA), an invaluable tool for studying polymer degradation.

\section{EXPERIMENTAL}

\subsection{Materials}

Flexible polyurethane foam was prepared in the University of Strathclyde following a patented flexible foam formulation. [18] The isocyanate employed was TDI (with an isocyanate index of 108) and the polyol was Alcupol F-5611 (a trifunctional polyether polyol of molar mass $3000 \mathrm{~g} \mathrm{~mol}^{-1}$ and hydroxyl index $56 \mathrm{mg} \mathrm{KOH} \mathrm{g}^{-1}$ ). Typically, the isocyanate was incorporated at a level of 46 parts per hundred polyol (pph). Water (3 pph) was employed as the blowing agent and the catalysts employed were dimethylethanolamine (DMEA, $0.3 \mathrm{pph}$ ), triethylenediamine (Dabco 33LV, $0.3 \mathrm{pph}$ ) and stannous octoate (Kosmos 29, 0.8 pph). A silicone-based surfactant (L620LV, 1 pph) was also employed. It should be noted that the levels of surfactant and catalyst present are sufficiently low to assume that these do not participate in or affect the degradation reactions which occur.

\subsection{Thermogravimetric Analysis (TGA)}

All TGA experiments were carried out using a Perkin Elmer TGA7 thermogravimetric analyzer with 3-5 mg cylindrical foam samples being analysed. The system was initially heated to $50^{\circ} \mathrm{C}$ and held isothermally for five minutes. Following this, the sample was heated at a rate of $10^{\circ} \mathrm{C} \mathrm{min}^{-1}$ from $50^{\circ} \mathrm{C}$ to $800^{\circ} \mathrm{C}$ under a flow of $30 \mathrm{ml} \mathrm{min}{ }^{-1}$ of helium. The mass loss as a function of temperature was monitored and from this the first derivative of the mass loss curve was calculated as a function of temperature. The temperature at which the onset of degradation occurs has been determined from the 
TGA curves and will be reported herein as the temperature at which the material has lost $5 \%$ of its original weight.

\subsection{Thermal Volatilisation Analysis (TVA)}

All TVA analyses were carried out using a TVA line which was built in-house, based upon the apparatus and techniques described by McNeill et al.[19] The apparatus consisted of a sample chamber (heated by a programmable tube furnace) connected in series to a primary liquid nitrogen cooled subambient trap. The whole system was continuously pumped to a vacuum of $1 \times 10^{-4}$ Torr by means of a two stage rotary pump and oil diffusion pumping system. Volatile condensable products could be initially trapped at two stages: the water jacket cooled 'cold-ring' immediately above the heated area of sample tube which condenses high boiling point materials which are not volatile under vacuum at ambient temperature, and the primary liquid nitrogen cooled sub-ambient trap which collected all the lower boiling point species which are volatile under vacuum at ambient temperature but which condense under vacuum at liquid nitrogen temperatures. A linear response Pirani gauge positioned at the entrance of the primary sub-ambient trap monitored the evolution of the total volatiles (condensable and noncondensable species) from the sample as a function of pressure vs. temperature/time. A second Pirani gauge at the exit of the primary sub-ambient trap monitored the evolution of the non-condensable volatiles (carbon monoxide, methane, hydrogen) as a function of pressure vs. temperature/time. Trapped, low-boiling species could be distilled into separate secondary cold traps by slowly heating the primary sub-ambient trap to ambient temperatures. These fractions could be subsequently removed into gas-phase cells for FTIR and GC-MS analysis. A series of non-linear Pirani gauges were placed at the entrance and exits of all secondary traps to monitor the pressure changes as volatile species were distilled into separate traps and gas-phase IR cells.

All dynamic TVA runs were conducted under vacuum using $25 \mathrm{mg}$ samples, with the samples heated from ambient temperature to $550^{\circ} \mathrm{C}$ at a rate of $10^{\circ} \mathrm{C} \mathrm{min}^{-1}$. For the isothermal TVA experiments $50 \mathrm{mg}$ samples were heated to the chosen temperature $\left(250,300,350\right.$ or $\left.400^{\circ} \mathrm{C}\right)$ at a rate of $10^{\circ} \mathrm{C} \mathrm{min}^{-1}$ 
and held isothermally for 30 minutes. A 1-300 amu Hiden single quadrapole RGA mass spectrometer sampled a continuous product stream during both the degradation and differential distillation runs. Subambient differential distillation of the collected volatiles was carried out by heating the primary subambient trap from $-196^{\circ} \mathrm{C}$ to ambient temperature. Volatiles were separated into four major fractions for subsequent IR and GC-MS analysis.

All FTIR analysis of the collected TVA products was carried out using a Perkin Elmer Spectrum 100 FTIR Spectrometer used in transmission mode. High boiling 'cold-ring' fractions were cast from chloroform solution onto $\mathrm{NaCl}$ disks for analysis. Low-boiling volatiles were analyzed in the gas phase using gas phase cells with $\mathrm{NaCl}$ windows.

All GC-MS analyses of the collected TVA products were carried out using a Finnigan ThermoQuest capillary column trace GC and Finnigan Polaris Quadrapole Mass Spectrometer. Coldring fractions and high molar mass products were dissolved in spectroscopy grade chloroform and subsequently analysed.

\section{RESULTS AND DISCUSSION}

\subsection{TGA}

TGA was employed in this study to examine the overall non-oxidative thermal degradation behaviour of the polyurethane foam. Presented in Figure 2 are the TGA mass loss curve and the corresponding DTG curve obtained for the polyurethane foam. A two stage mass loss is observed which suggests that degradation of the polyurethane occurs in two steps under an inert atmosphere. Significant mass loss is evident from $260^{\circ} \mathrm{C}$ and continues until approximately $410^{\circ} \mathrm{C}$, after which a slow continual mass loss occurs until $800^{\circ} \mathrm{C}$. A negligible residue remains at the end of the analysis which indicates that the foam does not yield a significant char under an inert atmosphere. The first degradation step has a maximum rate of mass loss at $290^{\circ} \mathrm{C}$ and is proposed to correspond to degradation of the urethane linkages within the foam by one or more of the mechanisms shown in figure 1. The second step, which is proposed to involve secondary degradation processes, has a maximum rate of mass loss at $370^{\circ} \mathrm{C}$. 
The mass loss observed for the second degradation step is greater than for the first which indicates that the secondary degradation processes, such as degradation of the polyol component of the foam, yield more volatile material than degradation of the urethane linkages.

\subsection{Dynamic TVA}

TGA is a useful technique for examining the overall degradation behaviour of a polymer; however, it does not provide any information regarding the nature of the degradation products which are evolved. The technique of TVA, on the other hand, allows the volatile degradation products to be separated into four different fractions which can be characterised, as well as allowing for the characterisation of high molar mass degradation products.

\section{- Degradation Profile}

The TVA degradation profile for the polyurethane foam, showing the rate of volatiles evolution as a function of furnace temperature, is presented in Figure 3. The corresponding onset degradation and evolution rate peak maxima temperatures are summarised in Table 1. Two peaks are observed in the TVA degradation profile; however, these peaks are not fully resolved which indicates the presence of multiple volatile degradation products which overlap to produce the observed peaks. The presence of two main peaks is in correlation with the TGA results; however, the temperatures at which these two peaks occur in the TVA profile differ from those obtained from the TGA under inert atmospheres. In TVA the sample is heated under vacuum and the onset of degradation and peak maxima appear at lower temperatures. Whilst the degradation is not influenced by the presence of a vacuum, the volatilisation of the degradation products is facilitated under vacuum and this leads to the onset of mass loss/volatilisation occurring at lower temperatures. It can be observed from Figure 3 that the first degradation step evolves a smaller quantity of volatile material than the second step; this is in agreement with the TGA results in which a greater mass loss was observed for the second degradation stage compared to the first. It is proposed that the first peak in the TVA profile arises from volatile products, such as CARBON DIOXIDE, which result from degradation of the urethane bonds within the foam by one of the mechanisms shown in Figure 1. The second step then involves secondary degradation 
reactions, primarily thermal degradation of the polyol component or polyol-based material which will have been regenerated during degradation of the urethane linkages. Finally, it can be observed from Figure 3 that small quantities of non-condensable volatiles were evolved during the thermal degradation of the polyurethane foam. These were identified by online MS as a mixture of carbon monoxide, methane and hydrogen. These volatiles are only present during the second degradation step and must, therefore, be associated with the secondary degradation reactions, most likely degradation of the polyol component of the foam.

During the thermal degradation of the polyurethane foam a pale yellow, liquid cold-ring fraction was collected and the FTIR spectrum of this is presented in Figure 4. The majority of the peaks are associated with structures which resemble the polyether polyol component of the foam. The peak at $1730 \mathrm{~cm}^{-1}$ could correspond to carbonyl-containing polyol fragments; however, it could also correspond to carbonyl groups within residual urethane linkages present in the cold-ring fraction. GC-MS analysis of the cold-ring fraction confirmed the presence of high molar mass polyol chain fragments and also revealed the presence of 2,4- and 2,6-TDI.

The results from the combined FTIR and GC-MS analyses, therefore, demonstrate that that the coldring fraction collected from the polyurethane foam is composed of TDI and high molar mass fragments derived from the polyether polyol chain. The presence of TDI within the cold-ring fraction confirms that degradation of the urethane bonds within the foam has occurred via a depolymerisation reaction to yield the isocyanate and regenerated polyol. The regenerated polyol is then proposed to degrade in the second step via random radical chain scission to yield the high molar mass chain fragments which are observed.

\section{- Differential Distillation and Characterisation of the Condensable Degradation Products}

The condensable volatiles collected from the polyurethane foam in the first stage of the analysis were separated into four different fractions by means of sub-ambient differential distillation and characterised by online MS and gas-phase FTIR analysis. Presented in Figure 5 is the sub-ambient 
differential distillation trace which provides a qualitative indication of the volatile degradation products which are evolved. The identities of each of the products evolved during the sub-ambient differential distillation are presented in Table 2. The major condensable degradation products identified are propene, carbon dioxide, formaldehyde, acetaldehyde, $\mathrm{C}_{3} \mathrm{H}_{6} \mathrm{O}$ isomers (e.g. propanal, propylene oxide, acetone) and high molar mass polyol chain fragments of various structures. All of these products, except for carbon dioxide, are likely to arise from the degradation of the polyol component of the foam. Carbon dioxide could arise from degradation of the urethane linkages via a six-membered ring transition state or a four-membered ring transition state similar to those shown in Figure 1. Carbon dioxide could also be present as a degradation product if the TDI evolved during the degradation of the urethane linkages undergoes a self-condensation reaction to form carbodiimide.

\subsection{Isothermal TVA}

In order to further probe the degradation chemistry of the polyurethane foam, isothermal TVA experiments were conducted at $250,300,350$ and $400^{\circ} \mathrm{C}$. These temperatures were chosen to represent the temperature range within which significant degradation of the polymer occurs.

\section{- Isothermal Profiles}

The TVA profile at $250^{\circ} \mathrm{C}$ showed only one peak corresponding to the evolution of a low level of degradation products that are volatile at ambient temperature. At this temperature these are most probably the degradation products associated with the primary degradation step of the polyurethane, i.e. the degradation of the urethane linkages. The volatiles may, however, also be associated with the degradation of the polyol component of the foam, if it begins to occur at this temperature. By $300^{\circ} \mathrm{C}$ there was still only one major peak observed in the TVA profile which indicates that the secondary degradation reactions have not reached their maximum rate at this temperature. There were no noncondensable volatiles detected at $250^{\circ} \mathrm{C}$ and $300^{\circ} \mathrm{C}$ which confirms that the degradation reactions which yield carbon monoxide, methane and hydrogen are not significant at these lower temperatures. 
By $350^{\circ} \mathrm{C}$ a significantly greater level of volatiles were evolved and the second degradation step became evident. Furthermore, a peak corresponding to the evolution of non-condensable volatiles (carbon monoxide, methane and hydrogen) was observed at $350^{\circ} \mathrm{C}$. This indicates that at temperatures between 300 and $350^{\circ} \mathrm{C}$ degradation of the polyol component of the foam has become significant and the reactions which yield non-condensable material have occurred. This is in agreement with TVA studies conducted by Grassie and Mendoza,[14] Costa et al.[17] and Cameron et al.[15] which revealed that the thermal degradation of polyether polyols occurs between $300^{\circ} \mathrm{C}$ and $500^{\circ} \mathrm{C}$, depending on the structure of the polyol. The TVA profile at $400^{\circ} \mathrm{C}$ showed little difference to that at $350^{\circ} \mathrm{C}$.

\section{- Cold-ring Fractions}

At $250^{\circ} \mathrm{C}$ a small amount of white, cloudy cold-ring fraction was observed. This was swabbed with chloroform and analysed by FTIR spectroscopy and GC-MS, however, due to the small amount of coldring fraction present the spectra were weak and showed no major peaks of interest. At $300^{\circ} \mathrm{C}$ the amount of cold-ring fraction collected was still small; however, the FTIR and GC-MS spectra showed peaks corresponding to TDI and polyol-based degradation products. By $350^{\circ} \mathrm{C}$ the cold-ring fraction was more significant and was identified as consisting of TDI and polyol-based degradation products, with similar results obtained for that at $400^{\circ} \mathrm{C}$. These results reveal that volatilisation of polyol-based degradation products occurs as low as $300^{\circ} \mathrm{C}$, which in turn indicates that degradation of the polyol also begins to occur at this temperature.

\section{- Residue}

During the isothermal degradation of the polyurethane it was observed that the foam structure collapsed into a clear liquid which was recovered from the base of the TVA tube following the degradations at 250,300 and $350^{\circ} \mathrm{C}$. These liquid residues were soluble in chloroform and were expected to primarily consist of polyol or polyol-based material which had been regenerated during the thermal degradation of the polyurethane foam. There was no residue remaining at $400^{\circ} \mathrm{C}$ which indicates that the foam has degraded completely by this temperature. The FTIR spectrum of the residue 
collected after the isothermal TVA at $250^{\circ} \mathrm{C}$ showed peaks associated with structures which resemble the polyether polyol component of the foam, as was expected to be the case. Comparison of the FTIR spectrum with that of the neat polyol (Figure 4) confirms that the residue consists of regenerated polyol. The spectrum of the residue is identical to that of the polyol expect for the additional small peak corresponding to carbonyl groups at $1731 \mathrm{~cm}^{-1}$, which indicates the presence of residual urethane linkages within the residue at $250^{\circ} \mathrm{C}$. The residues at $300^{\circ} \mathrm{C}$ and $350^{\circ} \mathrm{C}$ were identical to that at $250^{\circ} \mathrm{C}$, consisting of polyol regenerated during the primary degradation step. Carbonyl groups were still present within the residue at $350^{\circ} \mathrm{C}$, however, by this temperature it is expected that all of the urethane linkages within the residue will have fully degraded. It is, therefore, proposed that the residue now consists of degraded polyol which contains carbonyl groups within its structure.

\section{- Differential Distillation and Characterisation of the Condensable Degradation Products}

The condensable fractions collected during each isothermal experiment were separated by subambient differential distillation into four different fractions which were subsequently analysed by FTIR spectroscopy, online MS and GC-MS. The temperature ranges of the fractions collected and the identity of the products within each fraction are presented in Table 3. As the isothermal degradation temperature is increased greater quantities of condensable volatiles are evolved, and the product distribution becomes increasingly more complex. At $250^{\circ} \mathrm{C}$ the main products observed are carbon dioxide, water and higher molar mass species including TDI. Low levels of acetaldehyde and $\mathrm{C}_{3} \mathrm{H}_{6} \mathrm{O}$ isomers are also observed at this temperature. This is the temperature at which degradation of the urethane linkages is believed to occur, therefore, the presence of carbon dioxide and TDI indicate that there are two competing degradation mechanisms occurring for the urethane linkages within the polyurethane foam. The presence of acetaldehyde and $\mathrm{C}_{3} \mathrm{H}_{6} \mathrm{O}$ isomers at this temperature is surprising, indicating that degradation of the polyol has begun to occur at $250^{\circ} \mathrm{C}$. These volatiles are, however, only observed at a low level which suggests that the polyol degradation has not yet become significant. 
By $300^{\circ} \mathrm{C}$ the sub-ambient differential distillation trace is more complex, with additional degradation products such as formaldehyde and propene now observed. At $350^{\circ} \mathrm{C}$ the level of condensable volatiles evolved is significantly greater than at the lower temperatures which is indicative of significant polyol degradation occurring. This is in agreement with the TVA profile presented previously in which the secondary degradation peak was evident at $350^{\circ} \mathrm{C}$. There is no difference in the products distribution at $350^{\circ} \mathrm{C}$ and $400^{\circ} \mathrm{C}$ which indicates that no new degradation reactions which yield volatile material occur at $400^{\circ} \mathrm{C}$.

\subsection{Discussion and Proposed Mechanisms of Degradation}

The results from the TGA and TVA analysis show that the polyurethane foam undergoes a two stage degradation process under an inert atmosphere. The first stage can be attributed to degradation of the urethane linkages whilst the second stage is associated with secondary degradation reactions. Thermal degradation under helium occurs over the temperature range $260-400^{\circ} \mathrm{C}$, whilst under vacuum the onset of degradation and peak maxima appear to occur at lower temperatures. Whilst the degradation is not influenced by the presence of a vacuum, the volatilisation of the degradation products is facilitated under vacuum and this leads to the onset of mass loss/volatilisation occurring at a lower temperature. The dynamic TVA results revealed that both isomers of TDI were present in the cold-ring fraction which confirms that degradation of the urethane linkage within the foam occurs primarily via a depolymerisation reaction to yield ultimately the original monomers, as illustrated in Figure 6 . The presence of carbon dioxide, however, suggests that a second mechanism may be operating. Carbon dioxide could arise from degradation of the urethane linkage via either a six-membered ring transition state or a four-membered ring transition state similar to those shown in Figure 1. Both of these mechanisms lead to the formation of amines. However, no amines were identified during the analysis. It is likely that if these amines are produced they will react in the vapour phase with the regenerated TDI to form a polyurea as was observed by Ravey and Pearce.[4] A pale white waxy solid which was insoluble in most common solvents was recovered during the analysis of the polyurethane foam and the

FTIR spectrum of this material showed it to be a polyurea. Peaks were observed at $1634 \mathrm{~cm}^{-1}$ 
corresponding to carbonyl stretching and $1544 \mathrm{~cm}^{-1}$ corresponding to N-H stretching. The presence of polyurea, therefore, confirms that amines were evolved during the degradation of this foam and this, in conjunction with the presence of carbon dioxide, confirms that the urethane linkage degrades via both a depolymerisation reaction to yield TDI and polyol and a dissociation reaction to yield diaminotoluene (DAT), carbon dioxide and an alkene terminated polyol chain, as shown in Figures 6 and 7.

Carbon dioxide could also be present as a degradation product if the TDI which is evolved during degradation of the urethane linkages undergoes a self-condensation reaction to form carbodiimide. This reaction has been widely reported during the thermal degradation of MDI-based polyurethanes [5, 2022] with insoluble residues being recovered as a result. There was no evidence of carbodiimide formation during the TVA of the polyurethane foam in this study; therefore, it is unlikely that carbodiimide formation is the source of the carbon dioxide. The absence of carbodiimide during the TVA of the TDI-based foam is proposed to be a result of the greater volatility of the TDI under vacuum compared to the MDI. TDI has a lower molar mass than MDI and volatilisation into the cold-ring fraction will occur more readily. The self-condensation reaction is, therefore, less likely to occur during the degradation of a TDI-based foam.

The second degradation step can be attributed to secondary degradation reactions, in particular degradation of the polyol or alkene-terminated polyol chain which was regenerated during the primary degradation processes. The major condensable degradation products identified by TVA were propene, carbon dioxide, formaldehyde, acetaldehyde, $\mathrm{C}_{3} \mathrm{H}_{6} \mathrm{O}$ isomers (e.g. propanal, propylene oxide, acetone) and polyol chain fragments of various structures. These products all arise from degradation of the polyol component of the foam, except for carbon dioxide which arises in the first degradation step as explained above. It is proposed that degradation of the polyol occurs by random radical chain scission of the $\mathrm{C}-\mathrm{C}$ and $\mathrm{C}-\mathrm{O}$ bonds in the polymer backbone at the points shown in Figure 8 to yield the major condensable products. Degradation of the polyol component also leads to the formation of the non- 
condensable volatiles (carbon monoxide, methane and hydrogen) which were observed during the TVA studies.

The results from the isothermal TVA studies provide further insight into the degradation processes occurring within the foam. The presence of TDI and a polyol residue at $250^{\circ} \mathrm{C}$ confirms that degradation of the urethane linkages occurs via a depolymerisation. The presence of carbon dioxide at this temperature, however, indicates that the urethane linkages also degrade by dissociation via the sixmembered ring or four-membered ring transition states. There are, however, very few reports in the literature concerning the four-membered ring transition state occurring to any great extent. It is, therefore, most likely that the carbon dioxide arises from degradation of the urethane linkages via the six-membered ring transition state. This mechanism would lead to collapse of the foam to a liquid residue consisting of alkene-terminated polyol chains. Analysis of the residues recovered from the polyurethane foam, however, showed no peaks corresponding to $\mathrm{C}=\mathrm{C}$ groups within the residue. It is, therefore, proposed that degradation of the urethane linkages via a depolymerisation reaction to yield TDI and polyol is the predominant reaction which occurs for the polyurethane foam, which is in agreement with a number of studies published on thermal degradation of polyurethane. [5, 7, 8] The second, competing mechanism is proposed to be less significant for this particular polyurethane system under these conditions.

In addition to providing further information regarding the mechanism of degradation of the urethane linkages, the isothermal TVA studies also revealed more information regarding the degradation of the polyol component of the foam. The TVA profiles revealed that the second pressure peak, corresponding to the evolution of volatiles from thermal degradation of the polyol, and the noncondensable volatiles were not evident until temperatures above $300^{\circ} \mathrm{C}$. The cold-ring fractions, on the other hand, showed the presence of high molar mass polyol species at $300^{\circ} \mathrm{C}$, and characterisation of the condensable volatiles revealed low levels of polyol-derived volatiles such as acetaldehyde and formaldehyde at $250^{\circ} \mathrm{C}$ and $300^{\circ} \mathrm{C}$. Considering these results together it is, therefore, proposed that 
degradation of the polyol component of the foam under vacuum begins at temperatures as low as $250^{\circ} \mathrm{C}$ but does not yield a significant level of volatile material until temperatures higher than $300^{\circ} \mathrm{C}$. The TVA degradation profile of the neat polyol confirms this, with the evolution of volatile material commencing at $\sim 240^{\circ} \mathrm{C}$ but not reaching a maximum rate until $350^{\circ} \mathrm{C}$.

\section{CONCLUSIONS}

This work has demonstrated that the thermal degradation of a TDI-based polyurethane foam is a complex process which consists of competing mechanisms which yield an array of degradation products. The TGA results revealed the presence of a two step degradation mechanism, however, this yielded no information regarding the mechanisms which occur. The TVA results, on the other hand revealed that the initial degradation step corresponds to degradation of the urethane linkages by two competing mechanisms. The first mechanism, proposed to be the predominant mechanism, involves simple depolymerisation of the urethane bond to yield TDI and polyol. A second, competing mechanism is proposed to occur which involves dissociation of the urethane linkages to yield DAT, carbon dioxide and alkene-terminated polyol chains. The amines are then proposed to react in the vapour phase with the regenerated TDI to yield polyurea. The secondary degradation processes observed by TVA and TGA can be attributed primarily to degradation of the polyol which was regenerated in the first degradation step. Isothermal TVA studies revealed that this occurs as low as $250^{\circ} \mathrm{C}$ under vacuum but does not become significant until temperatures greater than $300^{\circ} \mathrm{C}$. Degradation of the polyol is proposed to occur by random radical chain scission to yield propene, formaldehyde, acetaldehyde, $\mathrm{C}_{3} \mathrm{H}_{6} \mathrm{O}$ isomers and high molar mass polyol chain fragments of various structures.

\section{REFERENCES}

[1] D.W. Hatchett, G. Kodipilli, J.W. Kinyanjui, F. Benincasa and L. Sapochak, Polym. Deg. Stab., 87, $555,(2005)$ 
[2] D.W. Hatchett, J.W. Kinyanjui and L. Sapochak, J. Cell. Plast., 183, 43, (2007)

[3] R.B. Mohan, B.J. O’Toole, J. Malpica, D.W. Hatchett, G. Kodipilli, J.W. Kinyanjui, J. Cell. Plast., $327,44,(2008)$

[4] M. Ravey and E. M. Pearce, J. Appl. Polym. Sci., 63, 47 (1997)

[5] N. Grassie and M. Zulfiqar, J. Polym. Sci.: Polym. Chem. Ed., 16, 1563 (1978)

[6] Y. Zhang, Z. Xia, H. Huang and H. Chen, Polym. Test., 28, 264 (2009)

[7] M. P. Thorne, Can. J. Chem., 45, 2537 (1967)

[8] L. Shufen, J. Zhi, Y. Kaijun, Y. Shuqin and W. K. Chow, J. Polymer-Plastics Technology and Engineering, 45, 95 (2006)

[9] N. Grassie, M. Zulfiqar and M. I. Guy, J. Poly. Sci. Pol. Chem., 18, 265 (1980)

[10] E. Dyer and G. C. Wright, J. Am. Chem. Soc., 81, 2138 (1959)

[11] A. F. McKay and G. R. Vavasour, Can. J. Chem., 31, 688 (1953)

[12] D. Randall and S. Lee, The Polyurethanes Book, John Wiley and Sons Ltd, Everberg, 2002, Ch. 2, p. 9

[13] J. H. Saunders and K. C. Frisch, Polyurethanes Chemistry and Technology: Part I. Chemistry, Interscience Publishers, New York, 1962, Ch. II, p. 32

[14] N. Grassie and A. P. Mendoza, Polym. Degrad. Stabil., 9, 155 (1984)

[15] G. G. Cameron, M. D. Ingram, M. Y. Qureshi, H. M. Gearing, L. Costa and G. Camino, Eur. Polym. J., 25, 779 (1989)

[16] J. Fan and J. C. W. Chien, Polym. Degrad. Stabil., 12, 43 (1985)

[17] L. Costa, G. Camino, M. P. Luda, G. G. Cameron and M. Y. Qureshi, Polym. Degrad. Stabil., 48, $325(1995)$

[18] J. H. Daly, J. J. Liggat, L. McCulloch and R. A. Pethrick, Fire Retarded Flexible Foam, UK Patent Application PCT/WO2009/007715

[19] I. C. McNeill, L. Ackerman, S. N. Gupta, M. Zulfiqar and S. Zulfiqar, J. Polym. Sci: Polym. Chem. Ed., 15, 2381 (1977) 
[20] N. Grassie and A. P. Mendoza, Polym. Degrad. Stabil., 10, 267 (1985)

[21] E. Dyer and G. E. Newborn Jr., J. Am. Chem. Soc., 80, 5495 (1958)

[22] S. T. Marks and E. Metcalfe, Combust. Flame., 107, 260 (1996)

\section{FIGURES}

Figure 1: Mechanisms of degradation of the urethane linkages. Mechanism I involves depolymerisation of the urethane group to yield the original isocyanates and polyol monomers. Mechanism II involves dissociation of the urethane group via a six-membered ring transition state to form a primary amine, an olefin and carbon dioxide. Mechanism III involves dissociation of the urethane group via a fourmembered ring transition state to form a secondary amine and carbon dioxide.

I

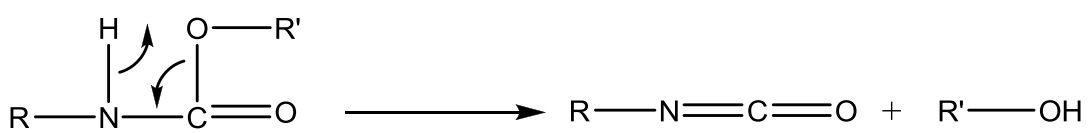

II

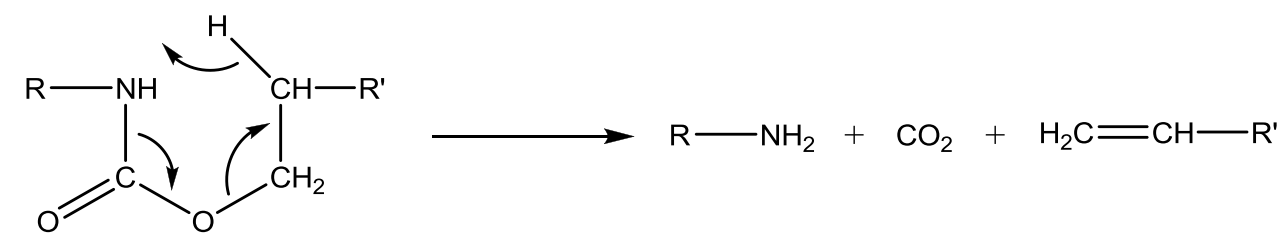

III

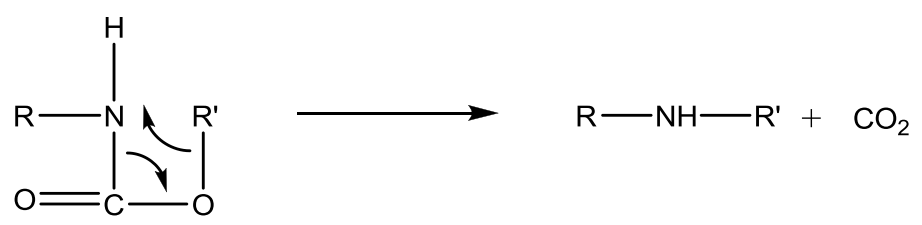


Figure 2: TGA (solid line) and DTG (dashed line) curves for the polyurethane foam.

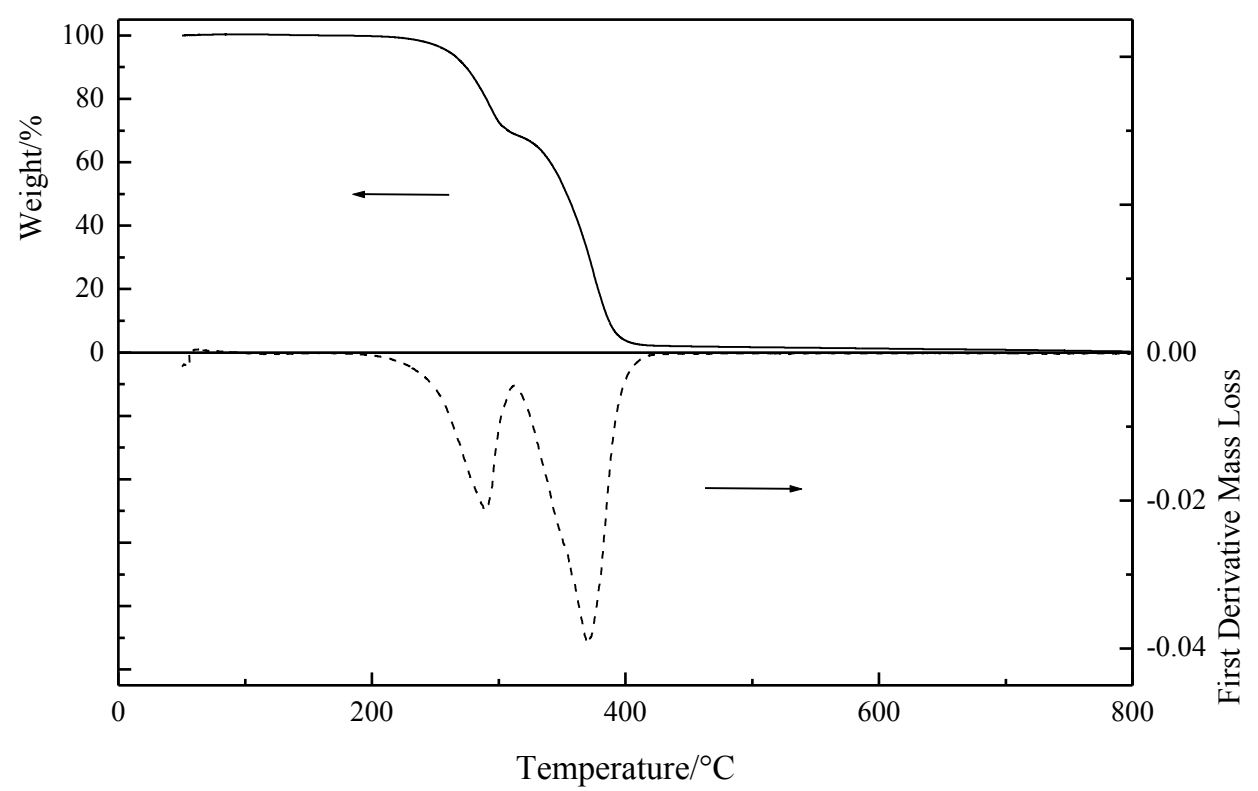


Figure 3: Dynamic TVA degradation profile for the polyurethane foam. The solid line represents all of the material which is volatile at room temperature (total volatiles) and the dashed line represents the permanent gases which pass through the cold trap (non-condensables).

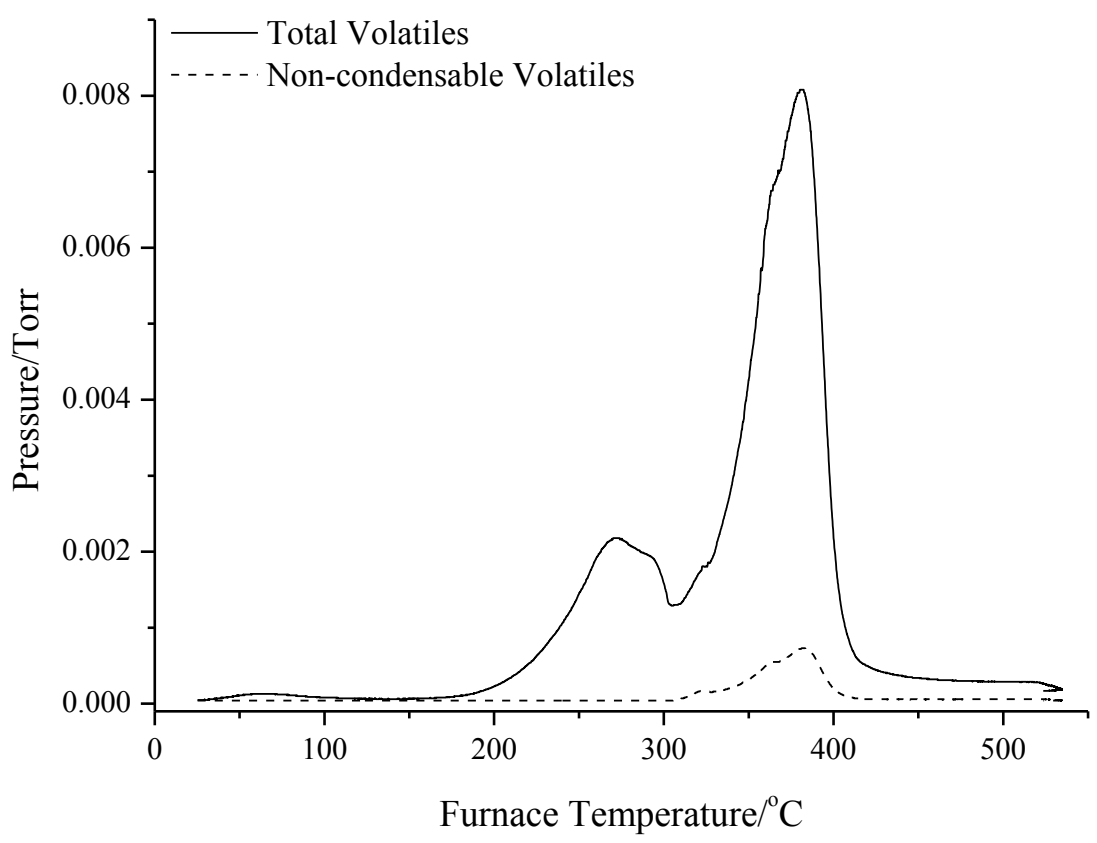


Figure 4: FTIR spectra of the original PU foam, the cold-ring fraction collected from the dynamic TVA, the residue collected from the foam following the TVA isothermal at $250^{\circ} \mathrm{C}$ and the neat polyol.

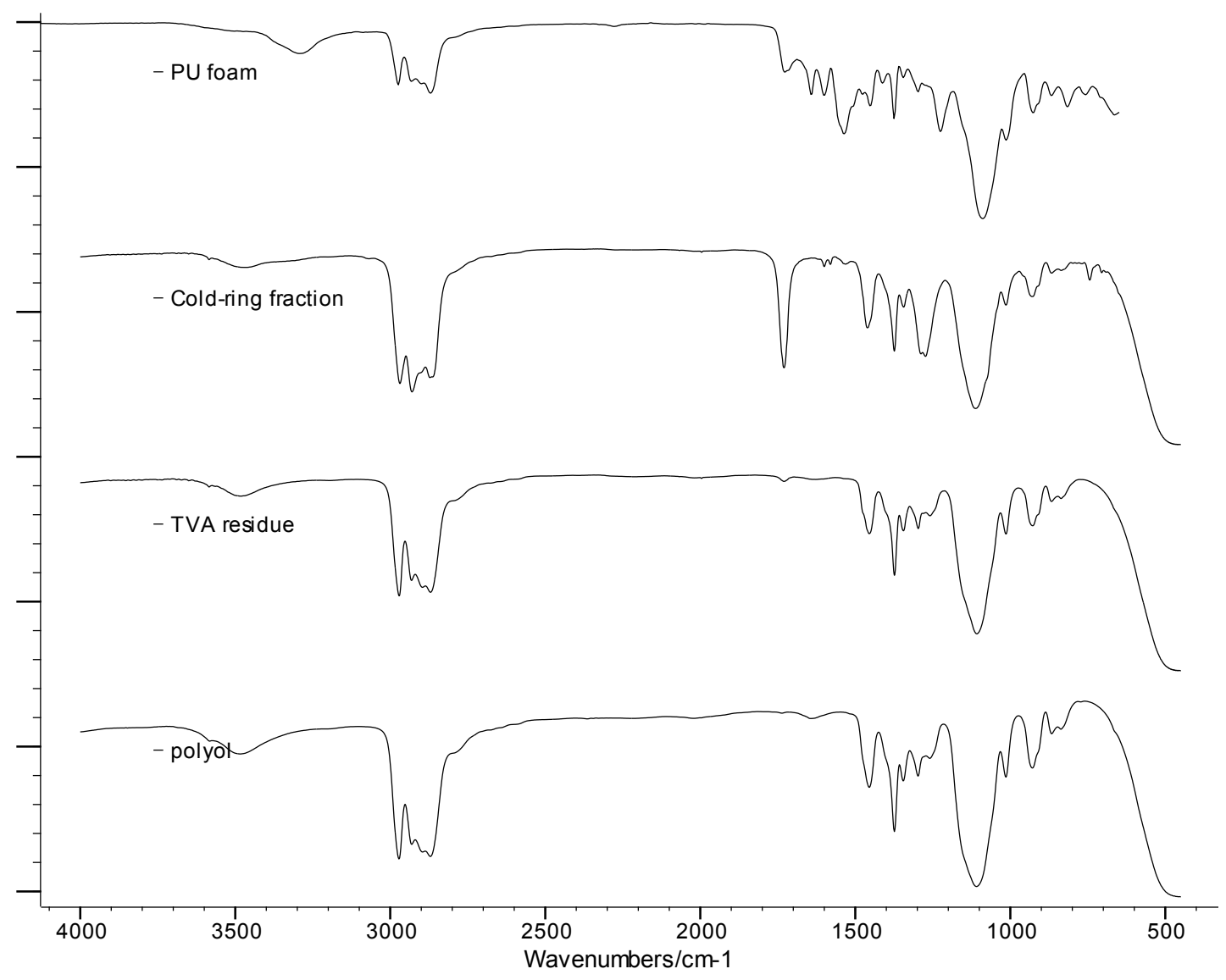


Figure 5: Sub-ambient differential distillation trace showing peaks which represent the different volatile degradation products evolved from the dynamic TVA of the polyurethane foam.

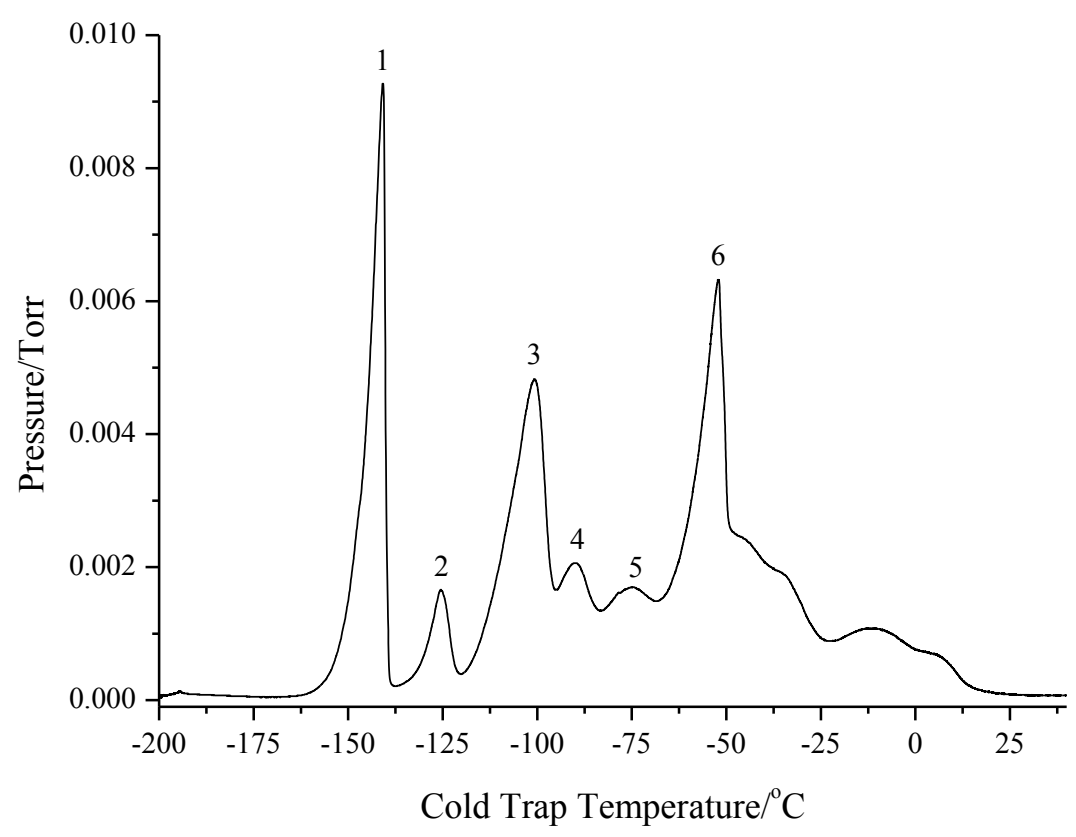


Figure 6: Degradation of the urethane linkage in the TDI-based polyurethane foam by a depolymerisation reaction.
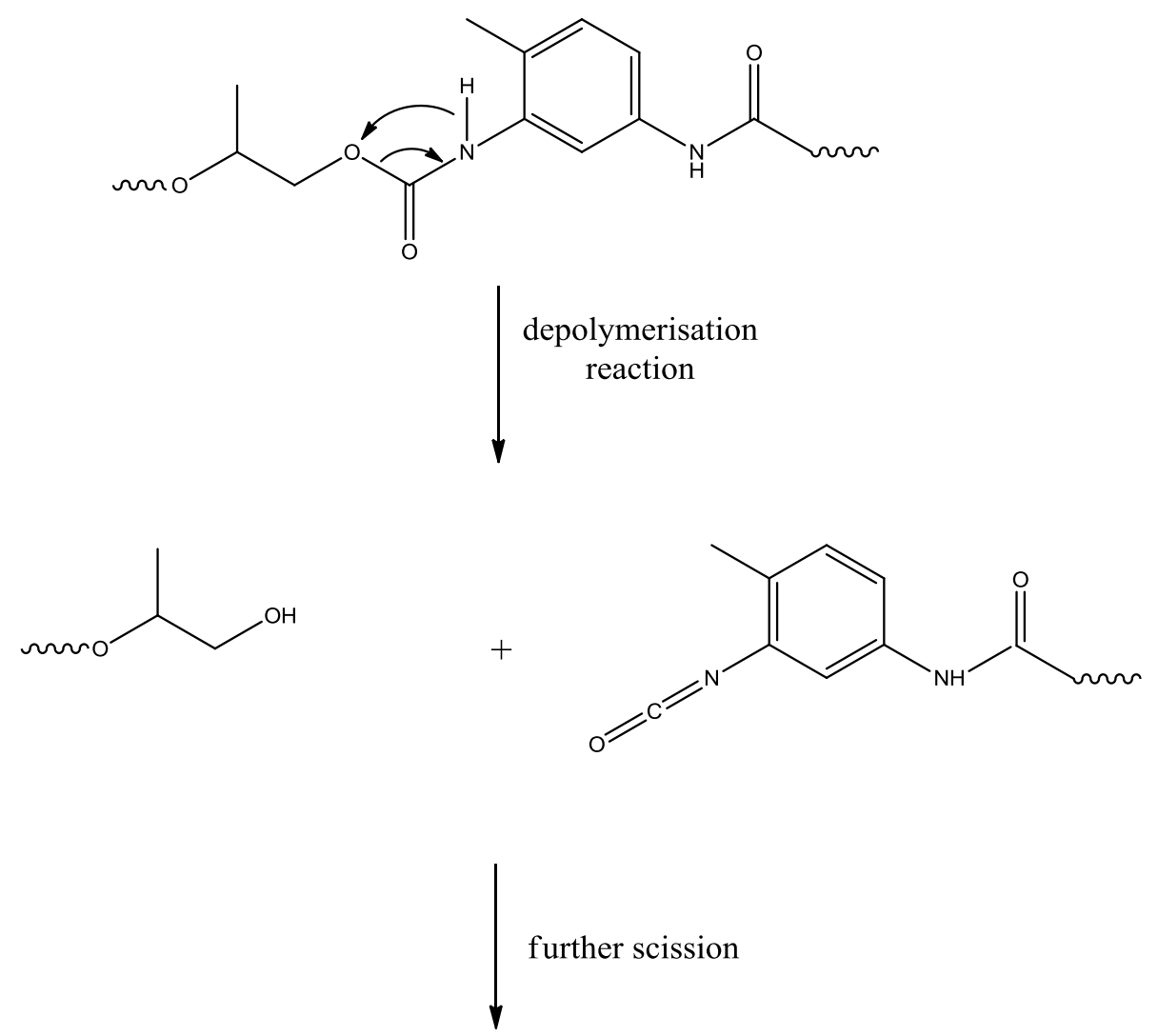

polyol + TDI 
Figure 7: Dissociation of the urethane linkage in the TDI-based polyurethane foam via a six-membered ring transition state to yield DAT, carbon dioxide and alkene-terminated polyol chains<smiles>COC(C)COC1(C)CCCCC1(C)OCC(=O)Nc1ccc(C)c(NC(C)(C)C)c1</smiles>

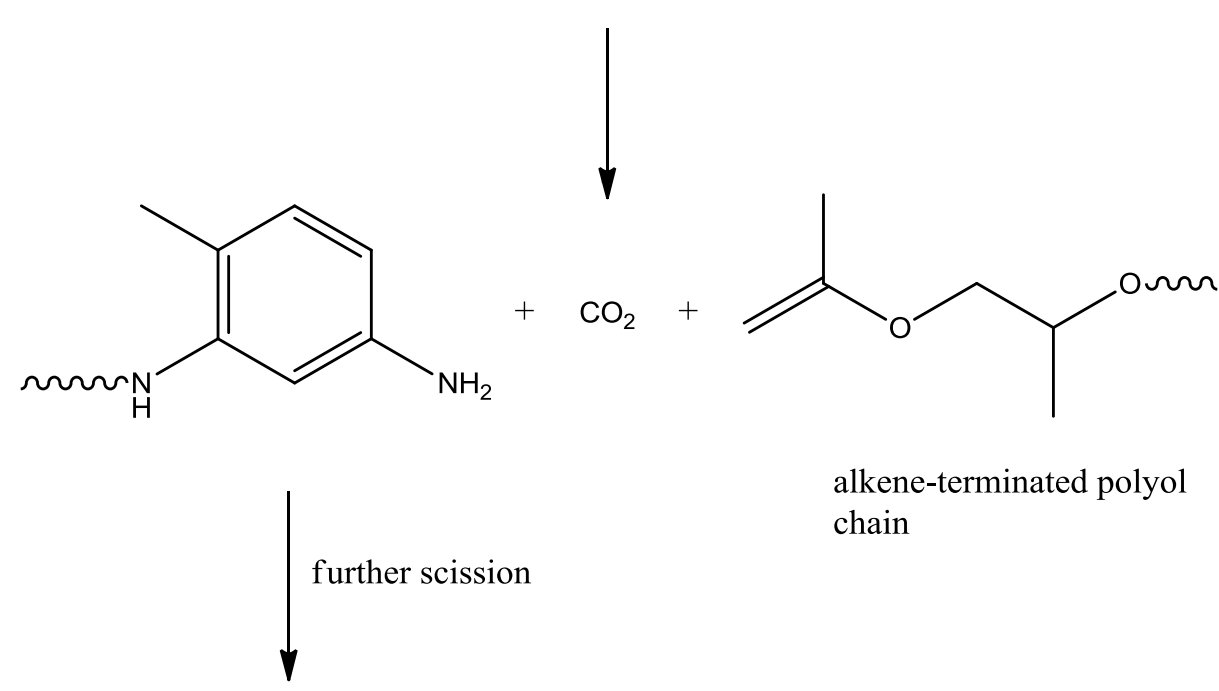

$\mathrm{DAT}+\mathrm{CO}_{2}+$ alkene terminated polyol chain 
Figure 8: Points of scission in the polyol chain which form the major condensable products.

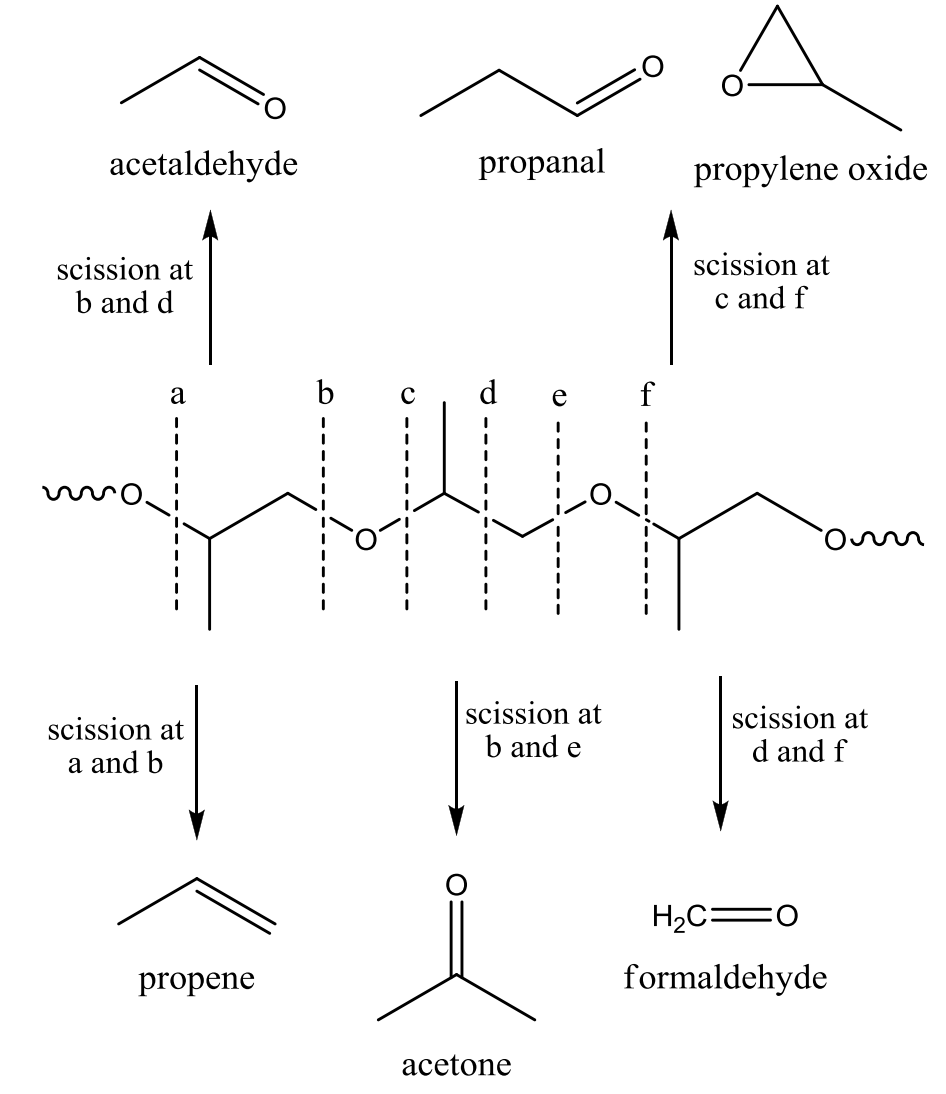




\section{TABLES}

Table 1: TVA onset degradation and maximum volatile evolution rate peak temperatures for the polyurethane foam.

\begin{tabular}{cc}
\hline Event & Temperature $/{ }^{\circ} \mathbf{C}$ \\
\hline Onset of volatile evolution & $\sim 145$ \\
\hline Peak 1 maximum rate of & \\
volatile evolution & \\
\hline Peak 2 maximum rate of \\
volatile evolution \\
\hline End of volatile evolution \\
\end{tabular}

Table 2: Sub-ambient differential distillation product identification for the polyurethane foam

\begin{tabular}{cc}
\hline Peak & Product Identification \\
\hline 1 & Propene and $\mathrm{CO}_{2}$ \\
\hline 2 & Formaldehyde \\
\hline 3 & Acetaldehyde \\
\hline 4 & $\mathrm{C}_{3} \mathrm{H}_{6} \mathrm{O}$ compound \\
\hline 5 & High molar mass polyol \\
& fragments \\
\hline 6 & Water and high molar \\
& mass polyol fragments \\
\hline
\end{tabular}


Table 3: Sub-ambient differential distillation product identifications for the isothermal TVA studies.

\begin{tabular}{|c|c|c|c|c|}
\hline \multirow{2}{*}{$\begin{array}{c}\text { Distillation } \\
\text { Temperature } \\
\text { Range }\end{array}$} & \multicolumn{4}{|c|}{ Product Identification } \\
\hline & $250^{\circ} \mathrm{C}$ & $300^{\circ} \mathrm{C}$ & $350^{\circ} \mathrm{C}$ & $400^{\circ} \mathrm{C}$ \\
\hline$-196^{\circ} \mathrm{C}$ to $-140^{\circ} \mathrm{C}$ & $\mathrm{CO}_{2}$ & Propene, $\mathrm{CO}_{2}$ & Propene, $\mathrm{CO}_{2}$ & Propene, $\mathrm{CO}_{2}$ \\
\hline$-140^{\circ} \mathrm{C}$ to $-60^{\circ} \mathrm{C}$ & $\begin{array}{l}\text { Acetaldehyde, } \\
\mathrm{C}_{3} \mathrm{H}_{6} \mathrm{O} \text { isomers }\end{array}$ & $\begin{array}{l}\text { Formaldehyde, } \\
\text { acetaldehyde, } \\
\mathrm{C}_{3} \mathrm{H}_{6} \mathrm{O} \text { isomers }\end{array}$ & $\begin{array}{l}\text { Formaldehyde, } \\
\text { acetaldehyde, } \\
\mathrm{C}_{3} \mathrm{H}_{6} \mathrm{O} \text { isomers }\end{array}$ & $\begin{array}{l}\text { Formaldehyde, } \\
\text { acetaldehyde, } \\
\mathrm{C}_{3} \mathrm{H}_{6} \mathrm{O} \text { isomers }\end{array}$ \\
\hline$-60^{\circ}$ to $-40^{\circ} \mathrm{C}$ & Water & Water & $\begin{array}{c}\text { Water and } \\
\text { high molar mass } \\
\text { polyol fragments }\end{array}$ & $\begin{array}{c}\text { Water and } \\
\text { high molar mass } \\
\text { polyol fragments }\end{array}$ \\
\hline$-40^{\circ} \mathrm{C}$ to $25^{\circ} \mathrm{C}$ & $\begin{array}{l}\text { High molar mass } \\
\text { polyol fragments, } \\
\text { TDI }\end{array}$ & $\begin{array}{c}\text { High molar mass } \\
\text { polyol fragments, } \\
\text { TDI }\end{array}$ & $\begin{array}{l}\text { High molar mass } \\
\text { polyol fragments }\end{array}$ & $\begin{array}{l}\text { High molar mass } \\
\text { polyol fragments }\end{array}$ \\
\hline
\end{tabular}

